Available online on 30.10.2020 at http://jddtonline.info
Open Access to Pharmaceutical and Medical Research
unrestricted non-commercial use, provided the original work is properly cited

Open 1 Access

Research Article

\title{
Gastroprotective and antioxidant properties of ethanolic extract from pear fruit (Pyrus communis L.)
}

\author{
Saliha Djidel, Amel Bouaziz* , Assia Bentahar and Seddik Khennouf \\ Laboratory of Phytotherapy Applied to Chronic Diseases, Faculty of Nature and Life Sciences, University Ferhat Abbas Setif 1, Setif, 19000,
} Algeria

\begin{abstract}
The objective of this study was to evaluate the phenolic content, in vitro antioxidant activity and the gastroprotective effect of the ethanolic extract of pear fruits (Pyrus communis L.). The amount of polyphenols and flavonoids contents of ethanolic extract were found to be $77,50 \pm$ $2,50 \mathrm{mg} \mathrm{GAE} / \mathrm{g}$ of dry extract and 0,31 $\pm 0,003 \mathrm{mg} \mathrm{QE} / \mathrm{g}$ of dry extract, respectively. Whereas the amount of tannins was $61,43 \pm 0,009 \mathrm{mg}$ $\mathrm{TAE} / \mathrm{g}$ of dry extract. Hydroxyl radical scavenging and reducing power tests were used to evaluate the antioxidant activities of this extract. The scavenging effect of ethanolic extract against hydroxyl radicals showed $\mathrm{IC}_{50}$ value of $2.71 \pm 0.02 \mathrm{mg} / \mathrm{ml}$. Reducing power test indicated the ability of ethanolic extract of pear fruits to reduce $\mathrm{Fe}^{+2}$ to $\mathrm{Fe}^{+3}$ with $\mathrm{EC}_{50}$ value of $1.043 \pm 0.01 \mathrm{mg} / \mathrm{ml}$. The treatment of rats with the ethanolic extract at dose of $200 \mathrm{mg} / \mathrm{kg}$ reduced the ulcerogenic effect of ethanol with value of protection rate of $94.44 \%$, but the protection rate decreased in $600 \mathrm{mg} / \mathrm{kg}$ treated group to $90.17 \%$. In conclusion, natural antioxidants derived from pear fruits can prevent gastric ulcer through their antioxidant activity
\end{abstract}

Keywords: Pyrus communis L., Polyphenols, Antioxidant activity, Ulcer, Rat.

Article Info: Received 07 Sep 2020; $\quad$ Review Completed 16 Oct 2020; $\quad$ Accepted 23 Oct 2020; Available online 30 Oct 2020

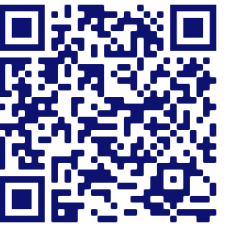

Cite this article as:

Djidel S, Bouaziz A, Bentahar A, Khennouf S, Gastroprotective and antioxidant properties of ethanolic extract fro m pear fruit (Pyrus communis L.), Journal of Drug Delivery and Therapeutics. 2020; 10(5):306-310 http://dx.doi.org/10.22270/jddt.v10i5.4538

*Address for Correspondence:

Amel Bouaziz, Laboratory of Phytotherapy Applied to Chronic Diseases, Faculty of Nature and Life Sciences, University Ferhat Abbas Setif 1, Setif, 19000, Algeria

\section{INTRODUCTION}

Free radicals present in the human organism cause oxidative damage to different molecules, such as lipids, proteins and nucleic acids and thus are involved in the initiation phase of some degenerative illnesses 1 . It has been demonstrated that these active oxygen species (ROS) might be involved in the formation of many diseases as gastric mucosal lesions 2 . Antioxidant systems have protected the body from the harmful effect of these free radicals. Endogenous antioxidants defense against the reactive oxygen species are strengthened by natural antioxidants that strengthen them and restore the optimal balance by neutralizing ROS 3 .

Fruits and vegetables are rich in antioxidants, such as vitamins and carotenoids, whose activities have been established in recent years. However, these compounds are not the only ones that contribute to the antioxidant activity of fruits and vegetables. Recent work shows that the presence of polyphenols, such as flavonoids in fruits and vegetables also contribute to the beneficial effects of this group of foods. Beside their biological properties, flavonoids are important in cosmetic and pharmaceutical industries, where they can be used as alternatives to synthetic antioxidants 1 .

Pear (Pyrus communis L.) is one of the most important temperate fruit crops of Rosaceae family and Pomoideae subfamily following apple. Pear is a good source of phytochemicals, especially phenolics, which are important bioactive compounds known for their health benefits. Health benefits of polyphenol consumption derived from their antioxidant and anti-inflammatory properties ${ }^{4}$. Other pro-health properties that are attributed to pear are related to the content of triterpenoids, due to their antioxidative, anti-inflammatory and anticancer properties 5 . Thus, the main objectives of this study were to determine the phenolic content, the antioxidant and gastroprotective activities of ethanolic extract of pear (Pyrus communis L.) fruit from Algeria. 


\section{MATERIALS AND METHODS}

\section{Collection of plant material and preparation of extract}

Fresh pear was purchased from Setif market (north of Algeria). The pear fruits were first cleaned and the seeds were removed, then $1 \mathrm{~kg}$ small pieces of pulp fruits were grinded. Markham method was used to extract the phenolic compounds. Briefly, $1 \mathrm{~kg}$ of sample was mixed with $5 \mathrm{~L}$ of ethanol-water mixture $(80: 20, \mathrm{v} / \mathrm{v})$ and kept at room temperature for 5 days ${ }^{6}$. The resulting solution was then filtered and the solvent was evaporated under reduced pressure to obatain ethanolic extract.

\section{Animals}

Mal albino rats, weighing 200-250g were obtained from Pasteur Institute in Algiers, Algeria, and were acclimatized for one week, prior to experiments. The animals were housed in an air-conditioned animal room, and maintained with free access to water and diet. The experimental protocol in rats was conducted after the experimental procedures were revised and approved by the Animal Ethics Committee of Institute of Nature and Life Sciences, University Ferhat Abbas, Setif 1, Algeria.

\section{Determination of total polyphenols content}

The total phenolics compounds of ethanolic extract were determined using the Folin-Ciocalteu test according to $\mathrm{Li}$ et al. 7. It depends on reduction of the components of the FolinCiocalteu reagent by the phenolic hydroxyl groups, forming a blue product in an alkaline medium. $0.1 \mathrm{ml}$ of pear extract was mixed with $0.5 \mathrm{ml}$ of Folin-Ciocalteau reagent (diluted 10 times). After $4 \mathrm{~min}, 0.4 \mathrm{ml}$ of $7.5 \%$ sodium carbonate $\left(\mathrm{Na}_{2} \mathrm{CO}_{3}\right)$ solution was added. After the incubation for $1 \mathrm{~h}$ and 30 min in the dark at room temperature, the absorbance was measured at $760 \mathrm{~nm}$ using a spectrophotometer and the results were expressed in mg of gallic acid equivalent per gram dry weight of plant (mg GAE /g DW).

\section{Determination of flavonoid content}

Flavonoid content of pear extract was calculated using the aluminum chlorine method, according to Bahorun et al. ${ }^{8} .1$ $\mathrm{ml}$ of pear extract was added to $1 \mathrm{ml}$ of aluminum chlorine solution (2\%). After 10 minutes of incubation in the dark, the absorbance was read using a spectrophotometer at 430 $\mathrm{nm}$. Results were expressed as quercetin equivalent per gram dried weight (mg QE /g DW).

\section{Determination of tannins content}

Efficacy of tannins to precipitate the hemoglobin was determined using the method of Gharzouli et al. 9. In brief, one volume of bovine fresh blood (absorbance $=1.6$ ) was added to a same volume of extract. After incubation for 20 minutes at room temperature, the mixture was centrifuged at $4000 \mathrm{rpm}$ for $10 \mathrm{~min}$, and the absorbance of the supernatant was measured at $756 \mathrm{~nm}$. Results were expressed as mg equivalent tannic acid per gram dried weight (mg TAE/g DW).

\section{Evaluation of antioxidant activity}

\section{Hydroxyl radical scavenging assay}

Hydroxyl radical scavenging activity was measured by the ability of ethanolic extract of pear fruit to scavenge the hydroxyl radicals using the method of Smirnoff and Cumbes 10 with slight modifications. The reaction mixture consists of $100 \mu \mathrm{L}$ of extract or standard antioxidants, $0.5 \mathrm{ml}$ of $\mathrm{FeSO}_{4}$ (1.5 mM), $0.35 \mathrm{ml}$ of $\mathrm{H}_{2} \mathrm{O}_{2}(6 \mathrm{mM}), 0.15 \mathrm{ml}$ of sodium salicylate $(20 \mathrm{mM})$. This mixture was incubated at $37 \mathrm{C}^{\circ}$ for $1 \mathrm{~h}$. The absorbance of the hydroxylated salicylate complex was measured at $562 \mathrm{~nm}$ and the scavenging effect was calculated as flows:

\section{Scavenging rate $=[$ Acontrol - Asample $] /$ Acontrol $\times 100$}

A control: was the absorbance of the control (without sample). A sample: the absorbance in the presence of the sample.

\section{Determination of reducing power}

The reducing power of extract was determined using the method of Chung et al. 11 . Briefly, $0.1 \mathrm{ml}$ of sample/standard, $0.1 \mathrm{ml} 0.2 \mathrm{M}$ phosphate buffer ( $\mathrm{pH} 6.6$ ) and $0.1 \mathrm{ml}$ of $1 \%$ potassium ferricyanide were mixed. After incubation at $50^{\circ}$ $\mathrm{C}$ for $20 \mathrm{~min}, 0.25 \mathrm{ml}$ of $1 \%$ trichloroacetic acid were added to the mixture followed by centrifugation at $3000 \mathrm{rpm}$ for 10 min. $0.25 \mathrm{ml}$ of the supernatant was mixed with $0.25 \mathrm{ml}$ distilled water and $0.5 \mathrm{ml}$ of $0.1 \%$ ferric chloride, and the absorbance of the resultant solution was read at $700 \mathrm{~nm}$. A standard was prepared using various concentrations of BHT.

\section{Gastric protective effect of pear extract}

Gastric protective effect of pear ethanolic extract was evaluated using the method described by Abdulla et al. 12 . The experimental animals were fasted for 24 hours with free access to water until 1 hour before the experiment. Afterthat, rats were divided into four groups, each group consisted of five rats as follows: the first group, which represented the negative control, received orally $1 \mathrm{ml}$ of distilled water; the second group, which represented the positive control, was treated with $1 \mathrm{ml}$ of omeprazole (20 $\mathrm{mg} / \mathrm{kg}$ ) , which was approved as a antiulcer agent. The third and fourth groups were treated with two doses of ethanolic extract of pear fruit $(200 \mathrm{mg} / \mathrm{kg}$ and $600 \mathrm{mg} / \mathrm{kg}$, respectively).

After an hour of treatment, each group received $0.5 \mathrm{ml}$ of ethanol, and after $30 \mathrm{~min}$, the rats of all groups were killed by cervical dislocation. The rats were dissected and the stomachs were removed and then opened according to the large curve, cleaned well with distilled water, and then fixed and photographed in order to calculate the area of ulcers using Image J. The gastric protective effect was calculated by the following formula:

The protection $\%=$ The rate of ulceration of the control - the rate of ulceration of the treatment / the rate of ulceration of the control x100.

\section{RESULTS AND DISCUSSION}

\section{Determination of total phenolic, flavonoid and tinnins content}

Phenolic compounds structurally differ from simple molecules, such as phenolic acids, and from highly polymerized compounds, such as proanthocyanidins (tannins), which found in plants and common in many foods (fruits, vegetables, cereal grains) and beverages (beer, teas) 13. The most common phenolics in human diet are phenolic acids, flavonoids and tannins ${ }^{14}$. In this study, The total phenolic and flavonoids contents in pear fruit ethanolic extract was determined to be 77,50 $\pm 2,50 \mathrm{mg} \mathrm{GAE} / \mathrm{g}$ and $0,31 \pm 0,003 \mathrm{mg} \mathrm{QE} / \mathrm{g}$ extract. Whereas the tannins content was $61,43 \pm 0,009 \mathrm{mg} \mathrm{TAE} / \mathrm{g}$ extract. Kolniac-ostec 15 have found the presence of different phenolic compounds in different parts of methanolic extract of pear using UPLC_PDA_MS method. 


\section{Antioxidant activity}

\section{Hydroxyl radical scavenging}

Hydroxyl radical is the most reactive oxygen species that induce severe damage to biomolecules ${ }^{16}$. Figure 1 showed that ethanolic extract of pear fruit and the reference antioxidant (vitamin C) had radical scavenging activities. In this study, pear fruit ethanolic extract has a good ability to scavenge hydroxyl radicals (IC50 $=2.71 \pm 0.02 \mathrm{mg} / \mathrm{ml}$ ) but it was significantly lower than vitamin C (IC50 $=0.084 \pm 0.007$ $\mathrm{mg} / \mathrm{ml}$ ). This scavenging effect could be attributed to the presence of polyphenols which can serve as free radical scavenger and hydrogen donner.

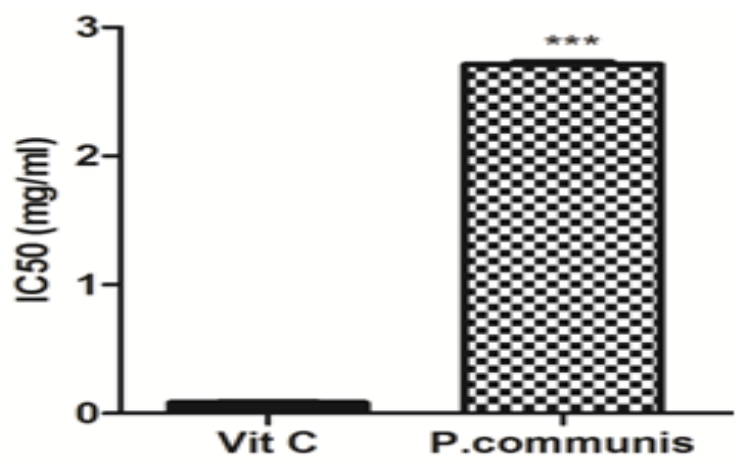

Figure 1: $\mathrm{IC}_{50}$ values of pear fruit extract and Vitamin $\mathrm{C}$ for hydroxyl radical scavenging activity. Lower $\mathrm{IC}_{50}$ value indicates higher antioxidant activity. Values are means $\pm \mathrm{SD}$ $(\mathrm{n}=3) \cdot\left({ }^{* * *} \mathrm{p}<0.001\right)$.

\section{Reducing power}

Reducing power reflects the ability of the active compounds to impart electrons, which is considered one of the antioxidant mechanisms. This ability can be revealed by transformation of $\mathrm{Fe}^{3+}$ to $\mathrm{Fe}^{2+}$ ion in the presence of extracts which served as an indicator of their antioxidant activity 17 . Figure 2 showed that ethanolic extract of pear fruit had a degree of electron donation capacity $($ EC50 $=1.043 \pm 0.01$ $\mathrm{mg} / \mathrm{ml}$ ), but the capacity was inferior to that of BHT ( EC50= $0.051 \pm 0.006 \mathrm{mg} / \mathrm{ml})$. The reducing power of the extract may be due to the presence of phenolic compounds. Similar relations between $\mathrm{Fe}^{3+}$ reducing activity and total phenol content have been reported in the literature 18,19 .

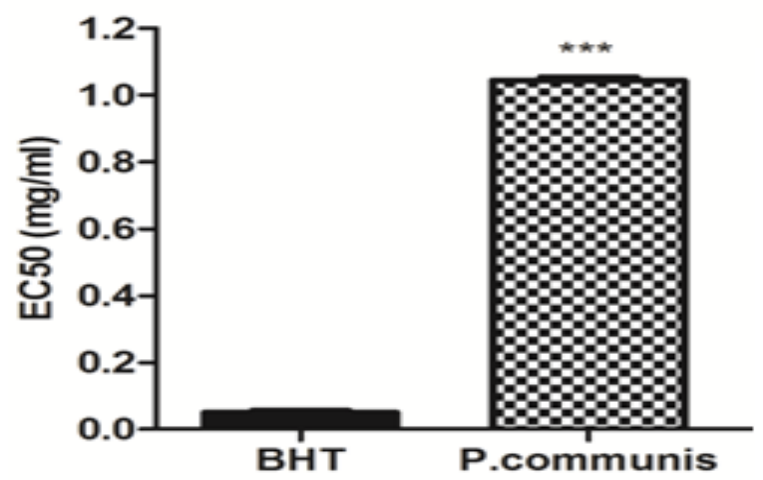

Figure 2: $\mathrm{EC}_{50}$ values of pear fruit extract and BHT for reducing power. Lower EC50 value indicates higher antioxidant activity. Values are means \pm SD $(n=3)$. $\left(^{* * *} \mathrm{p}<\right.$ 0.001).

\section{Gastric protect effect}

\section{Macroscopic observation of gastric mucosa after ethanol treatment}

Through the observation of the macroscopic stomach, it was found that treatment of rats with distilled water and treating them one hour later with ethanol at a dose of $2.5 \mathrm{ml}$ / kg led to ruptures at the level of the gastric mucosa (Figure 3- A). It was also evident that the mucus of rats treated with pear ethanolic extract at a dose of $200 \mathrm{mg} / \mathrm{kg}$ showed more protection, as some very slight ulcers were observed that were almost non-existent (figure 3-B) compared to the rats treated with doses of $600 \mathrm{mg} / \mathrm{kg}$. This later dose showed a lower protection ratio (Figure 3-C). Whereas, rats treated with $20 \mathrm{mg} / \mathrm{kg}$ of omeprazole achieved a very high protection rate (Figure 3-D).

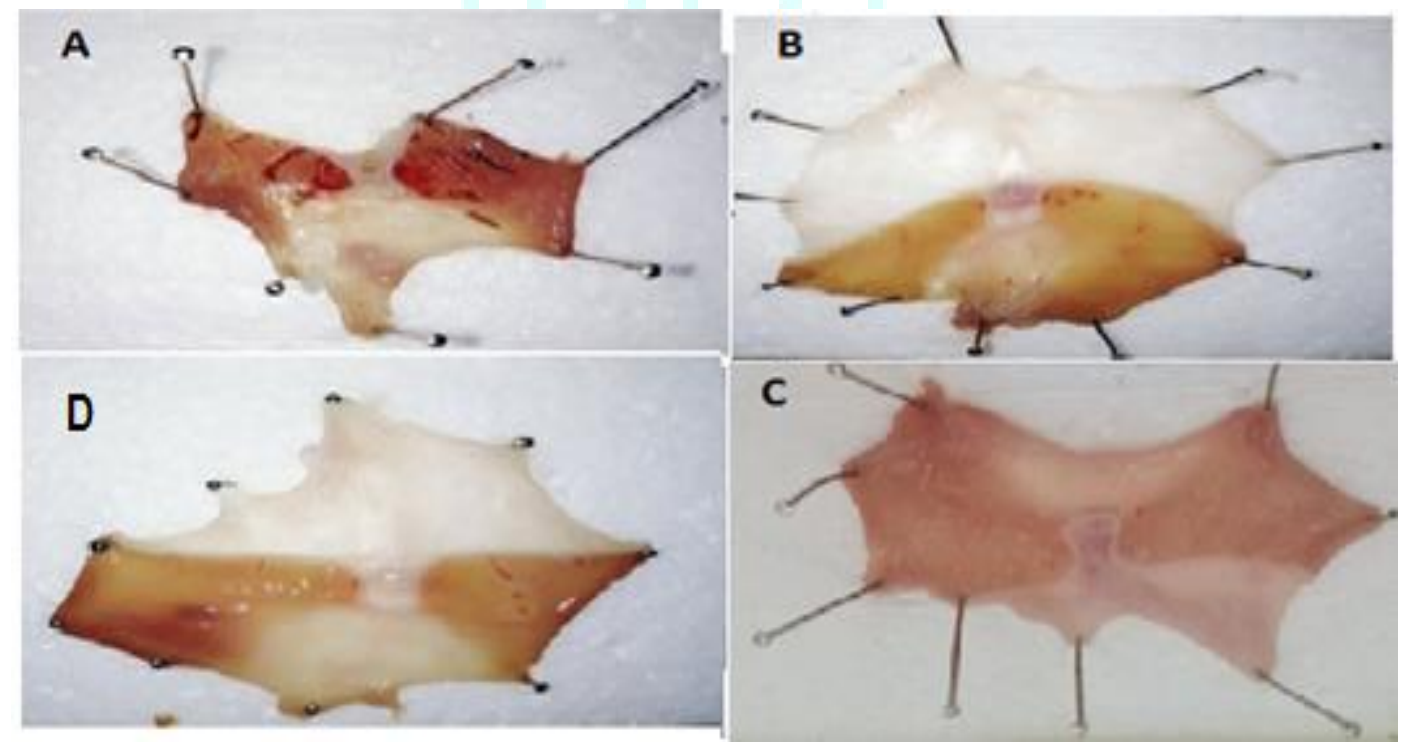

Figure 3: Effect of ethanolic extract of $P$. communis on gastric lesion examined in ethanol-induced gastric ulceration model in rats. A: injured control, B: pear extract (200 mg/kg), C: pear extract (600 mg/kg), D: omeprazole (20 mg/kg). 


\section{Ulcer index}

The first group, which was considered as a negative control, was treated with distilled water followed by ethanol with 2.5 $\mathrm{ml} / \mathrm{kg}$ led to the appearance of gastric ulceration with ulcer index percentage of $31.96 \pm 2.41 \%$. The second and third groups treated with ethanolic extracts at $200 \mathrm{mg} / \mathrm{kg}$ and 600 $\mathrm{mg} / \mathrm{kg}$ reduced the rate of ulceration to $1.77 \pm 0.48 \%$ and $3.14 \pm 0.48 \%$ respectively (Figure 4 ).

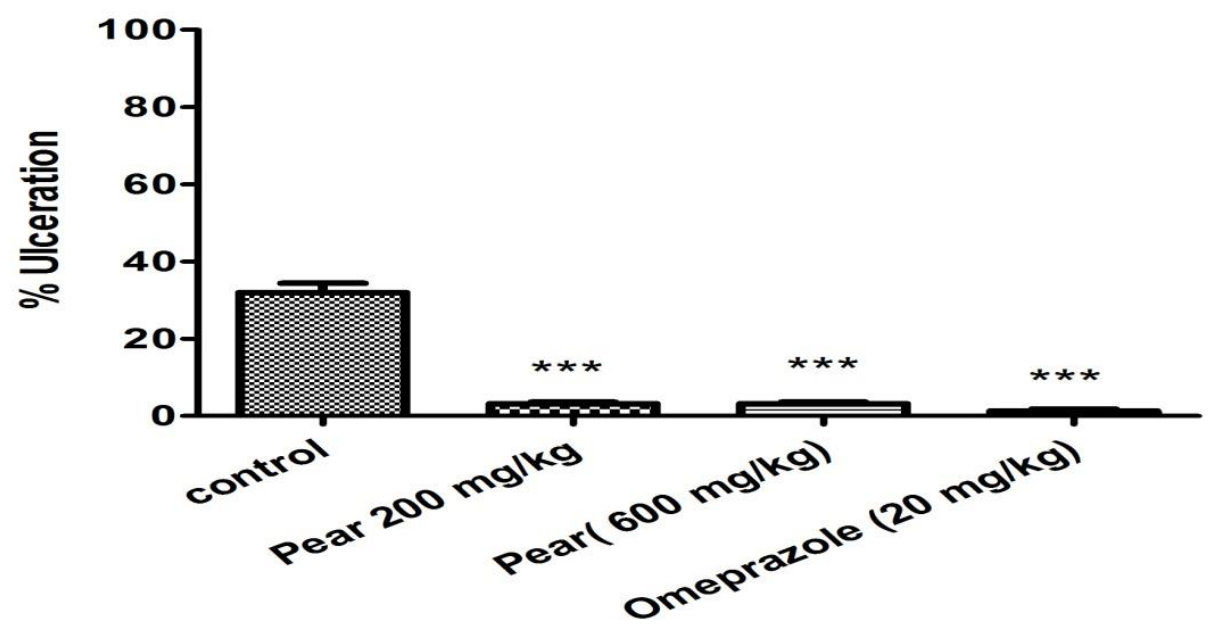

Figure 4: Percentage of ulceration after the pretreatment with pear ethanolic extract and omeprazole. Results are expressed as means \pm SEM $(\mathrm{n}=5) ;\left({ }^{* * *}: \mathrm{p}<0.001\right)$ compared to control group

Treatment of rats with ethanol resulted in ulcers characterizing the glandular part of the stomach, through its inhibition of mucus and bicarbonate secretion ${ }^{20}$. It also affects the action of 5-lipo oxygenases, the diffusion of $\mathrm{H}^{+}$ ions leading to direct damage of gastric mucosa and decreased blood flow ${ }^{21}$.

\section{Gastric protective effect}

Figure 5 showed that pear ethanolic extract $(200 \mathrm{mg} / \mathrm{kg})$ had the ability to protect the gastric mucosa at a rate of $94.44 \pm$ $1.34 \%$. This value was similar to the value recorded in the group treated with omeprazole at a dose of $20 \mathrm{mg} / \mathrm{kg}$ $(95.92 \pm 1.98 \%)$ with no significant difference $(\mathrm{p} \leq 0.05)$. While the protection rate decreased slightly in the group treated with the pear ethanolic extract at dose of $600 \mathrm{mg} / \mathrm{kg}$ $(90.17 \pm 1.50 \%)$.

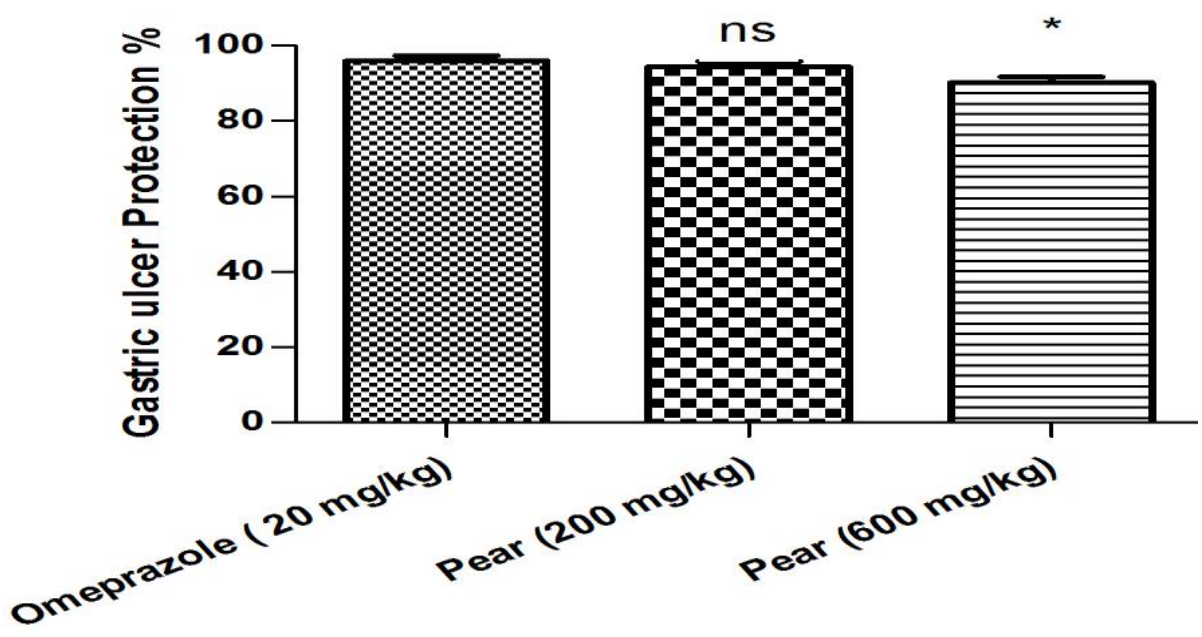

Figure 5: Percentage of Protection after the pretreatment with pear ethanolic extract of pear and omeprazole. Results are expressed as means \pm SEM $(n=5) ;\left(\right.$ ns: no significant difference, $\left.{ }^{*}: p<0.05\right)$ compared to omeprazole

The results of this study showed that the ethanolic extract of $P$. communis fruit was able to protect the stomach from ethanol-induced ulceration. The ability to protect the gastric mucosa can be attributed to its antioxidant properties, due to its richness in phenolic compounds. Studies have shown that the phenolic compounds present in the food extracts possess anti-ulcer activity [22]. They protect the gastric mucosa against a variety of ulcerogenic agents via several mechanisms of action, mainly free-radical scavenging and antioxidant properties, increased mucus production, antisecretory action, and inhibition of Helicobacter pylori growth. Tannins prevent ulcer development due to their protein precipitating and vasoconstricting effects. Their astringent action can help to precipitate microproteins on 
the ulcer site, thereby, forming an impervious layer over the lining, which hinders induced gastric ulcer in rats, as evidenced by the gut secretions, and protects the underlying mucosa from reduction in the ulcer scores 22.

\section{CONCLUSION}

This study revealed that the ethanolic extract of Pyrus communis L. exhibited remarkable free radical scavenging and reducing power, which may due to the presence of high polyphenolic content. It also showed that was able to protect against ulceration of the gastric mucosa caused by ethanol. This work suggests that the pear fruit can be a better source of phytochemicals. These compounds could be applied to great effect in the prevention of diseases associated with free radicals such as ulcer.

\section{ACKNOWLEDGEMENTS}

This work was supported by the Algerian Ministry of Higher Education and Scientific Research (MESRS), the Thematic Agency for Research in Health Sciences (ATRSS), and the General Directorate of Scientific Research and Technological Development (DGRSDT). We express our gratitude to these organizations.

\section{REFERENCES}

1. Garcla-Alonso M, de Pascual-Teresa S, Santos-Buelga C, RivasGonzalo JC, Evaluation of the antioxidant properties of fruits, Food Chemistry, 2004; 84:13-18.

2. Itoh $\mathrm{M}$, and Guth, $\mathrm{PH}$, Role of oxygen derived free radicals in hemorrhagic shock-induced gastric lesion in rat, Gastroenterology, 1985; 88:1162-1167.

3. Adwas AA, Elsayed ASI, Azab AE, Quwaydir FA, Oxidative stress and antioxidant mechanisms in human body, J Appl Biotechnol Bioen, 2019; 6(1): 43-47.

4. 4- Borges G, Mullen W, and Crozier A, Comparison of the polyphenolic composition and antioxidant activity of European commercial fruit juices, Food \& Function, 2010; 1:73-83.

5. Lesselier E, Destandau E, Grigoras C, Fougère L, Elfakir C, Fast separation of triterpenoids by supercritical fluid chromatography/evaporative light scattering detector, Journal of Chromatography A, 2012; 1268:157-165.

6. Markham KR, Techniques of Flavonoid Identification, London Academic Press, Chap. 1 and 2, 1982, p. 113.

7. Li HB, Cheng KW, Wong CC, Fan KW, Chen F, Jiang Y, Evaluation of antioxidant capacity and total phenolic content of different fractions of selected microalgae, Food chem, 2007; 102:771-776.
8. Bahorun T, Gressier B, Trotin F, Brunet C, Dine T, Luyck X, Oxygen species scavenging activity of phenolic extracts from hawthorn fresh plant organs and pharmaceutical preparations, Arzneimittelforschung, 1996; 46: 1086-1089.

9. Gharzouli K, Khennouf S, Amira S, Gharzouli A, Effects of aqueous extracts from Quercus ilex L. root bark, Punica granatum L. fruit peel and Artemisia herba-alba Asso leaves on ethanol-induced gastric damage in rats, Phytother Res, 1999; 13:42-45.

10. Smirnoff N, Cumbes QJ, Hydroxyl radical scavenging activity of compatible solutes, Journal of Phytochemistry, 1989; 28: 1057 $-1060$.

11. Chung YC, Chen SJ, Hsu CK, Chang CT, Chou ST, Studies on the antioxidative activity of Graptopetalum paraguayense, Food Chemistry, 2005; 91:419-424.

12. Abdulla MA, Ahmed KAA, Al Bayaty FH, Masood Y. Gastroprotective effect of Phyllanthus niruri leaf extract against ethanol-induced gastric mucosal injury in rats. Afr J Pharma Pharmacol, 2010; 4:226 -630.

13. Santos-Buelga C, Sacalbert A, Proanthocyanidins and TanninLike Compounds-Nature, Occurrence, Dietary Intake and effects on nutrition and health. Journal of the Science and Food Agriculture, 2000; 80:1094-1117.

14. King A, Young G, (1999) Characteristics and Occurrence of Phenolic Phytochemicals. Journal of the American Dietetic Association, 1999; 99:213-218.

15. Kolniak-Ostek J, Chemical composition and antioxidant capacity of different anatomical parts of pear (Pyrus communis L.), Food Chemistry, 2016; 203:491-497.

16. Sakanaka S, Tachibana Y, Okada Y, Preparation and antioxidant properties of extracts of Japanese persimmon leaf tea (kakinoha-cha), Food Chem, 2005; 89:569-575.

17. Gülçin l, Topal F, Sarıkaya SBÖ, Bursal E, Bilsel G, Gören AC, Polyphenol Contents and Antioxidant Properties of Medlar (Mespilus germanica L.), Rec Nat Prod, 2011; 5(3):158-175.

18. Djidel S, khennouf $S$, Radical scavenging, reducing power, lipid peroxidation inhibition and chelating properties of extracts from Artemisia campestris L. Aerial Parts, Annual Research \& Review in Biology, 2014; 4(10):1691-1702.

19. Bouaziz A, Khennouf S, Abu zarga M, Abdalla S, Baghiani A, Charef N, Phytochemical analysis, hypotensive effect and antioxidant properties of Myrtus communis L. growing in Algeria. Asian Pac J Trop Biomed., 2015; 5:19-28.

20. Ishida $K$, Kojima $R$, Tsuboi $M$, Tsuda $Y$, Ito $M$, Effects of artichoke leaf extract on acute gastric mucosal injury in rats, Biol. Pharm. Bull, 2010; 33(2):223-229.

21. 20- Jamal A, Javed K, Aslam M, Jafri MA, Gastroprotective effect of cardamom, Elettaria cardamomum Maton fruitsin rats, J Ethnopharmacol, 2006;103:149-153.

22. Sumbul S, Ahmad MA, Mohd A, Mohd A, Role of phenolic compounds in peptic ulcer: An overview, J Pharm Bioallied Sci, 2011; 3(3):361-367. 